\title{
INFLAMMATORY BOWEL DISEASE
}

\section{Interleukin 10 genotypes in irritable bowel syndrome: evidence for an inflammatory component?}

\author{
W M Gonsalkorale, C Perrey, V Pravica, P J Whorwell, I V Hutchinson
}

Gut 2003;52:91-93

See end of article for authors' affiliations

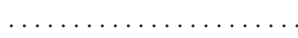

Correspondence to: Dr W M Gonsalkorale, Department of Medicine, University Hospital of South Manchester, Nell Lane, Manchester M20 2LR, UK; wgonsalkorale@compuserve. com

Accepted for publication 26 July 2002

\begin{abstract}
Background and aims: Inflammation may play a role in the pathogenesis of irritable bowel syndrome in some individuals, such as in those who develop symptoms following a dysenteric illness. Persisting inflammation, resulting from an imbalance of cytokines regulating the inflammatory response, is one possible mechanism. As the elaboration of cytokines is under genetic control, this study was designed to establish whether there might be a genetic predisposition to an altered pattern of anti-inflammatory cytokine production in patients with irritable bowel syndrome.

Subjects: A total of 230 unselected patients with irritable bowel syndrome and 450 healthy, ethnically matched controls were studied.

Methods: DNA was extracted from peripheral blood leucocytes of subjects. Allele and genotype frequencies were determined for the anti-inflammatory cytokine interleukin 10 at the site $(-1082)$ concerned with production in lymphocytes. Transforming growth factor $\beta_{1}$ (codons 10 and 25) genotypes were also examined in a smaller group of subjects.

Results: Patients with irritable bowel syndrome had significantly reduced frequencies of the high producer genotype for interleukin 10 than controls $(21 \% \vee 32 \% ; p=0.003)$. There was no apparent relationship with any particular bowel habit subtype. Genotypes for transforming growth factor $\beta_{1}$ were not altered.

Conclusions: These preliminary results suggest that at least some patients with irritable bowel syndrome may be genetically predisposed to produce lower amounts of the anti-inflammatory cytokine interleukin 10. This lends some support to the hypothesis that there may be an inflammatory or genetic component in some cases of this condition and that further studies in specific irritable bowel syndrome subgroups are justified.
\end{abstract}

rritable bowel syndrome (IBS) is a multifactorial disorder and a number of pathophysiological mechanisms have been proposed, including abnormalities of motility, ${ }^{12}$ visceral sensation, ${ }^{3}$ and even alterations of gut fermentation. ${ }^{4}$ In addition, psychological factors are important in at least some patients. ${ }^{5}$ There is also a familial tendency to IBS and, although this could be psychosocial in origin, a genetic influence is a possibility.

More recently, it has been proposed that inflammation may play a role in IBS, based on several lines of evidence. ${ }^{6}$ For instance, increased numbers of mast cells have been found in the terminal ileum of IBS patients ${ }^{78}$ and some patients with ulcerative colitis have IBS-like symptoms when in remission. ${ }^{9}$ In addition, a substantial proportion of cases are apparently precipitated by gastrointestinal infection ${ }^{10-12}$ where a continuing inflammatory response has been demonstrated. ${ }^{13}$

The production of cytokines is under genetic control, and these molecules are involved in the regulation of immune and inflammatory responses. Some, including tumour necrosis factor $\alpha$ and interferon $\gamma$, are proinflammatory while others, such as interleukin 10 (IL-10) and transforming growth factor $\beta_{1}\left(\right.$ TGF- $\left.\beta_{1}\right)$, have anti-inflammatory properties. By studying the polymorphisms in the genes coding for these cytokines, alleles associated with high or low production ("high" or "low" producer alleles) have been identified. ${ }^{14-17}$ Thus individuals can be divided into high, intermediate, and low producers of a particular cytokine, those who are homozygous for the high producer allele making the highest amounts, those homozygous for the low producer allele the least, while heterozygotes have intermediate levels.

The genetic predisposition to produce higher or lower amounts of a particular cytokine may alter susceptibility to certain diseases or affect their clinical expression. For example, possession of the high producer allele at position -308 in the gene coding for tumour necrosis factor $\alpha$ is associated with worse outcome in cerebral malaria. ${ }^{18}$ Mice lacking the IL-10 gene spontaneously develop a form of enterocolitis. ${ }^{19}$ We have previously shown that patients with ulcerative colitis are more likely to have genotypes associated with lower IL-10 production. ${ }^{20}$

The aim of this study therefore was to test the hypothesis that if there is an inflammatory component in some cases of IBS, there may be a genetic predisposition for an altered pattern of production of the anti-inflammatory cytokines IL-10 and TGF- $\beta_{1}$ in such individuals.

\section{METHODS}

\section{Study subjects}

Blood samples were obtained, after informed consent, from 230 consecutive patients fulfilling the Rome I criteria for $\mathrm{IBS}^{21}$ attending the Gastroenterology Out-Patients Clinic. Patients were of all bowel habit subtypes, $24 \%$ being constipation predominant, $38 \%$ being diarrhoea predominant, and a further $38 \%$ having an alternating pattern. A total of 450 ethnically matched controls were used for comparison. Initially, only the IL-10 genotype was assessed but subsequently preliminary screening of TGF- $\beta_{1}$ genotypes was also carried out on 134 patients and 127 controls. The study was approved by the local ethics committee.

Abbreviations: IL-10, interleukin-10; IBS, irritable bowel syndrome; TGF- $\beta_{1}$, transforming growth factor $\beta_{1}$; OR, odds ratio; PI-IBS, post infective irritable bowel syndrome. 
Table 1 Interleukin 10 (IL-10) (-1082) polymorphism allele and genotype distribution

\begin{tabular}{|c|c|c|c|c|}
\hline & \multicolumn{2}{|c|}{ IBS $(n=230)$} & \multicolumn{2}{|c|}{ Controls $(n=450)$} \\
\hline & $\mathrm{n}$ & $\%$ & $\mathrm{n}$ & $\%$ \\
\hline \multicolumn{5}{|l|}{ IL-10 } \\
\hline \multicolumn{5}{|l|}{ Allele frequency§ } \\
\hline$-1082^{*} G$ (high) & 219 & $48^{*}$ & 438 & 52 \\
\hline$-1082 * A$ (low) & 241 & 52 & 412 & 48 \\
\hline \multicolumn{5}{|l|}{ Genotypeף } \\
\hline G/G (high producer) & 49 & $21 \dagger$ & 135 & 32 \\
\hline G/A (intermediate) & 121 & 53 & 168 & 39 \\
\hline A/A (low producer) & 60 & 26 & 122 & 29 \\
\hline \multicolumn{5}{|l|}{ Genotype } \\
\hline$A-(G / G)$ & 49 & $21 \ddagger$ & 135 & 32 \\
\hline $\mathrm{A}+(\mathrm{A} / \mathrm{A}$ or $\mathrm{G} / \mathrm{A})$ & 181 & 79 & 290 & 68 \\
\hline \multicolumn{5}{|c|}{$\begin{array}{l}\text { *Odds ratio (OR) } 1.17(95 \% \text { confidence interval } 0.93-1.49) ; \\
p=0.097 . \\
\text { tFewer irritable bowel syndrome (IBS) patients of high producer } \\
(\mathrm{G} / \mathrm{G}) \text { genotype }\left(\chi^{2}=11.97, \mathrm{df}=2, p=0.003\right) \text {, with more patients } \\
\text { carrying } \mathrm{A} \text { allele }(\mathrm{A}+\mathrm{G} / \mathrm{A} \text { or } \mathrm{A} / \mathrm{A})\left(\chi^{2}=8.08, \mathrm{OR} 1.72(1.18-2.50) \text {, }\right. \\
\mathrm{p}=0.004) \neq . \\
\S n=\text { number of alleles in each group, being twice the number of } \\
\text { individuals as two alleles are inherited. } \\
\text { In=number of individuals with specific genotype. }\end{array}$} \\
\hline
\end{tabular}

\section{Genotyping methods}

Genomic DNA was extracted from peripheral blood leucocytes and genotyping carried out by amplification refractory mutational system-polymerase chain reaction methods, as previously described, ${ }^{22}{ }^{23}$ using allele specific primers to identify the high and low producer alleles of each biallelic polymorphic site of the IL- 10 gene $(-1082 * \mathrm{G}$ and $-1082 * \mathrm{~A}$, respectively) and the TGF- $\beta_{1}$ gene $\left(+869^{*} \mathrm{~T}\right.$ and $+869^{*} \mathrm{C}$, respectively, codon $10 ;+915^{*} \mathrm{G}$ and $+915^{*} \mathrm{C}$, respectively, codon 25$)$. Amplified DNA products were then analysed using electrophoresis on $2 \%$ agarose gel and viewed under UV light.

\section{Statistical analysis}

Allele frequencies for patients and controls were compared by calculation of the odds ratio (OR) and 95\% confidence intervals (95\% CI). Genotypes were calculated for each individual, with those homozygous for the high producer allele classed as "high producer", heterozygotes as "intermediate producer", and those homozygous for the low producer allele as "low producer" genotype, respectively. ${ }^{15}{ }^{19}$ Genotype frequencies were then compared by $\chi^{2}$ analysis.

\section{RESULTS}

Table 1 shows allele and genotype frequencies for IL-10. The frequency of the high producer $-1082 * \mathrm{G}$ allele was slightly lower in IBS patients but this did not reach statistical significance (IBS $v$ controls: 48\% v 52\%; $\mathrm{p}=0.097$ ). However, genotype frequencies were found to differ in that there were significantly fewer IBS patients with the high producer $\left(-1082^{*} \mathrm{G} / \mathrm{G}\right)$ genotype (IBS $v$ controls: $21 \% v 32 \%$; $\mathrm{p}=0.003$ ), and with an increased proportion of patients being positive for the A allele, being either the low producer genotype $-1082 * \mathrm{~A} / \mathrm{A}$ or the heterozygous $-1082^{*} \mathrm{G} / \mathrm{A}$ (IBS $v$ controls: $79 \%$ v $68 \% ; \mathrm{p}=0.004)$. No comparison between bowel habit subtypes was possible because of insufficient numbers in each subgroup. However, there was no obvious relationship between a reduced high producer genotype and a particular pattern of bowel habit.

Allele and genotype frequencies for TGF- $\beta_{1}$ were no different in IBS patients and controls either at codon 10 (IBS $v$ controls: allele frequency: $+869 \mathrm{~T}$ (high producer allele): $61 \% \mathrm{v}$ $63 \%$, OR 0.91 (95\% CI 0.63-1.30), $\mathrm{p}=0.593$; genotype frequencies: $+869 \mathrm{~T} / \mathrm{T}: 39 \%$ v 39\%; T/C: $44 \%$ v $48 \%$; C/C: $17 \%$ v $13 \%$; $\chi^{2}=1.07, \mathrm{p}=0.584$ ) or at codon 25 (IBS $v$ controls: allele frequency: +915G (high producer allele): 91\% v 91\%, OR 1.05 (0.57-1.97), $\mathrm{p}=1.00$; genotype frequencies: $+915 \mathrm{G} / \mathrm{G}: 84 \% v$ $82 \% ; \mathrm{G} / \mathrm{C}: 13 \% \vee 17 \% ; \mathrm{C} / \mathrm{C}: 3 \%$ v $\left.1 \% ; \chi^{2}=2.22, \mathrm{p}=0.330\right)$.

\section{DISCUSSION}

The results of this study demonstrate a significant association between IL-10 genotypes and IBS, with fewer patients having the high producer genotype compared with healthy controls. The lower prevalence of the high producer genotype in IBS suggests that high production of IL-10 may have some protective role or, conversely, that individuals predisposed to produce lower amounts of this cytokine might be more likely to develop the condition. A genetic predisposition to lower antiinflammatory cytokine production could mean that control of the inflammatory response may be compromised in some individuals and may help to explain why gastrointestinal infections, for example, can sometimes lead to continuing problems. It is possible that an inflammatory process is perpetuated by failure of downregulation secondary to an inadequate anti-inflammatory cytokine response.

There are a number of points however that need to be considered in the interpretation of these findings. IL-10 is only one of the anti-inflammatory cytokines involved in regulation of immune and inflammatory responses, and the possible involvement of other cytokines in the inflammatory process cannot be ruled out. However, examination of allelic and genotypic frequencies for the biallelic polymorphisms of TGF- $\beta_{1}$, albeit on a smaller number of patients, did not reveal any significant differences from healthy controls. The IL-10 gene does have a number of different polymorphisms but the site selected in this study $(-1082)$ is known to influence IL-10 production in lymphocytes, and differences in IL-10 levels have been measured in serum and from activated peripheral blood cells. ${ }^{15} 2024$ Lymphocytes have been found in excessive numbers in the intestinal mucosa in cases of post infective irritable bowel syndrome (PI-IBS) $)^{13}$ but the question of whether in vivo IL-10 production within the intestine is similarly influenced by genotype remains to be addressed.

IBS is almost certainly a multifactorial condition with different combinations of factors operating in any one individual. Thus it is likely that a certain facet of the condition under genetic control will only account for a relatively small proportion of patients. Furthermore, if that facet has no biological marker, identifying appropriate subgroups for more indepth evaluation presents difficulties. At first sight, PI-IBS might seem a relatively straightforward group to study but this will inevitably contain patients with pre-existing forme fruste IBS as well as de novo cases, either of which might have the genetic trait under scrutiny. Similar pitfalls could accompany another potentially fruitful line of enquiry-that is, those patients with a family history. It is highly likely that this group could contain patients in whom learning from parents is just as important as inheritance from the same.

This study was not powered to assess an association between our findings and any particular characteristic of the condition, such as diarrhoea, constipation, bloating, pain, or even apparent precipitation by dysentery. However, the fact that in such an unselected group of patients a significant trend emerged strongly suggests that it might contain a subgroup in whom genes controlling inflammation might be important and this warrants further investigation.

Future studies on PI-IBS will have to be very carefully designed to ensure homogeneity of the groups under study as far as possible. This should include documenting the infecting organism, not forgetting viruses, considering measurement of markers of inflammation, both serological and mucosal, and possibly assessing gastrointestinal physiology or mucosal permeability. In addition, the role of dietary antigens may also have to be taken into account. 
In conclusion, the association found between IL-10 genotype frequencies in an unselected group of IBS patients suggests there may be a subgroup of patients in whom this gene is critically important to the development of their disease. In addition, these results provide some support for the concept that genetic factors may also contribute to the pathogenesis of this condition.

\section{ACKNOWLEDGEMENTS}

We thank Aashish Tagore and Joyce Chan for assistance in sample collection.

\section{Authors' affiliations}

W M Gonsalkorale, P J Whorwell, Department of Medicine, University Hospital of South Manchester, Nell Lane, Manchester M2O 2LR, UK C Perrey, V Pravica, I V Hutchinson, Immunology Research Group, School of Biological Sciences, University of Manchester, Oxford Road, Manchester M13 8TP, UK

\section{REFERENCES}

1 Quigley EMM. Disturbances in small bowel motility. In: Houghton LA, Whorwell PJ, eds. Clinical gastroenterology: Irritable bowel syndrome Baillière's best practice and research, vol 13 . London: Baillière Tindall, 1999:385-96.

2 Spiller RC. Disturbances in large bowel motility. In: Houghton LA, Whorwell PJ, eds. Clinical gastroenterology: Irritable bowel syndrome. Baillière's best practice and research, vol 13. London: Baillière Tindall, 1999:397-414.

3 Houghton LA. Sensory dysfunction and the irritable bowel syndrome. In: Houghton LA, Whorwell PJ, eds. Clinical gastroenterology: Irritable bowel syndrome. Baillière's best practice and research, vol 13. London: Baillière Tindall, 1999:415-28.

4 King TS, Elia $M$, Hunter JO. Abnormal colonic fermentation in irritable bowel syndrome. Lancet 1998;352:1187-9.

5 Drossman DA, Creed FH, Fava GA, et al. Psychosocial aspects of the functional gastrointestinal disorders. Gastroenterol Int 1995;8:47-90.

6 Collins SM, Piche T, Rampal P. The putative role of inflammation in the irritable bowel syndrome. Gut 2001;49:743-5.

7 Weston AP, Biddle WL, Bhatia PS, et al. Terminal ileal mucosal mast cells in irritable bowel syndrome. Dig Dis Sci 1993;38:1590-5.

8 O'Sullivan M, Breslin NP, Harman I, et al. Increased mucosal mast cells-evidence of an inflammatory response in IBS. Gut 1999;44(suppl 1):A132.

9 Isgar B, Harman M, Kaye MD, et al. Symptoms of irritable bowel syndrome in ulcerative colitis in remission. Gut 1983;24:190-2.
10 Bergin AJ, Donnelly TC, McKendrick MW, et al. Changes in ano-rectal function in persistent bowel disturbance following salmonella gastroenteritis. Eur J Gastroenterol Hepatol 1993;5:617-20.

11 Gwee KA Graham JC, McKendrick MW et al. Psychometric scores and persistence of irritable bowel syndrome after infectious diarrhoea. Lancet 1996;346: 150-3.

12 Neal KR, Hebden J, Spiller R. Prevalence of gastrointestinal symptoms six months after bacterial gastroenteritis and risk factors for development of the irritable bowel syndrome: postal survey of patients. BM 1997;314:779-82.

13 Spiller RC, Jenkins D, Thornley JP, et al. Increased rectal mucosal enteroendocrine cells, T lymphocytes, and increased gut permeability following acute Campylobacter enteritis and in post-dysenteric irritable bowel syndrome. Gut 2000;47:804-11.

14 Wilson GA, Symons JA, McDowell TL, et al. Effects of a polymoprhism in the human fumor necrosis factor promoter on transcriptional activation. Proc Natl Acad Sci USA 1997;94:3195-9.

15 Turner DM, Williams DM, Sankaran D, et al. An investigation of polymorphism in the interleukin-10 gene promoter. Eur J Immunogenetics 1997;24:1-8.

16 Awad MR, El-Gamel A, Simm E, et al. Genotypic variation in the transforming growth factor-beta 1 gene: association with TGF- $\beta_{1}$ production, fibrotic lung disease and graft fibrosis after lung transplantation. Transplantation 1998;66:1014-20.

17 Pravica V, Asderakis A, Perrey C, et al. In vitro production of IFN- $\gamma$ correlates with CA repeat polymorphism in the human IFN- $\gamma$ gene. Eur J Immunogenet 1999:26:1-3.

18 McGuire W, Hill AV, Allsopp CE, et al. Variation in the TNF-alpha promoter region associated with susceptibility to cerebral malaria. Nature 1994;371:508-10.

19 Kuhn R, Lohler J, Rennick D, et al. Interleukin-10 deficient mice develop chronic enterocolitis. Cell 1993;75:263-74.

20 Tagore A, Gonsalkorale WM, Pravica V, et al. Interleukin-10 (IL-10) genotypes in inflammatory bowel disease. Tissue Antigens 1999;54:386-90.

21 Thomspon WG, Creed F, Drossman DA, et al. Functional bowel disorders and functional abdominal pain. Gastroenterol Int 1992;5:75-91.

22 Perrey C, Turner SJ, Pravica V, et al. ARMS-PCR methodologies to determine IL-10, TNF- $\alpha$, and TGF- $\beta_{1}$ gene polymorphisms. Transplant Immunol 1999;7:127-8.

23 Perrey C, Pravica V, Sinnott PJ, et al. Genotyping for polymorphisms in interferon- $\gamma$, interleukin- 10 , transforming growth factor- $\beta_{1}$ and tumour necrosis factor- $\alpha$ genes: a technical report. Transpl Immunol 1998;6: 193-7.

24 Crawley E, Kay R, Sillibourne J, et al. Polymorphic haplotypes of the IL-10 5' flanking region determine variable interleukin-10 transcription and are associated with particular phenotypes of juvenile rheumatoid arthritis. Arthritis Rheum 1999;42:1101-8. 